\title{
ANALYSIS OF RISK FACTORS FOR SURGICAL SITE INFECTION: A CASE RESEARCH IN AN ORTHOPEDIC HOSPITAL (HEALTHCARE INDUSTRY)
}

\author{
R.K.A.Bhalaji ${ }^{1 *}$, S.Bathrinath ${ }^{1}$, S.G.Ponnambalam ${ }^{2}$ and 1 S.Saravanasankar ${ }^{1}$
}

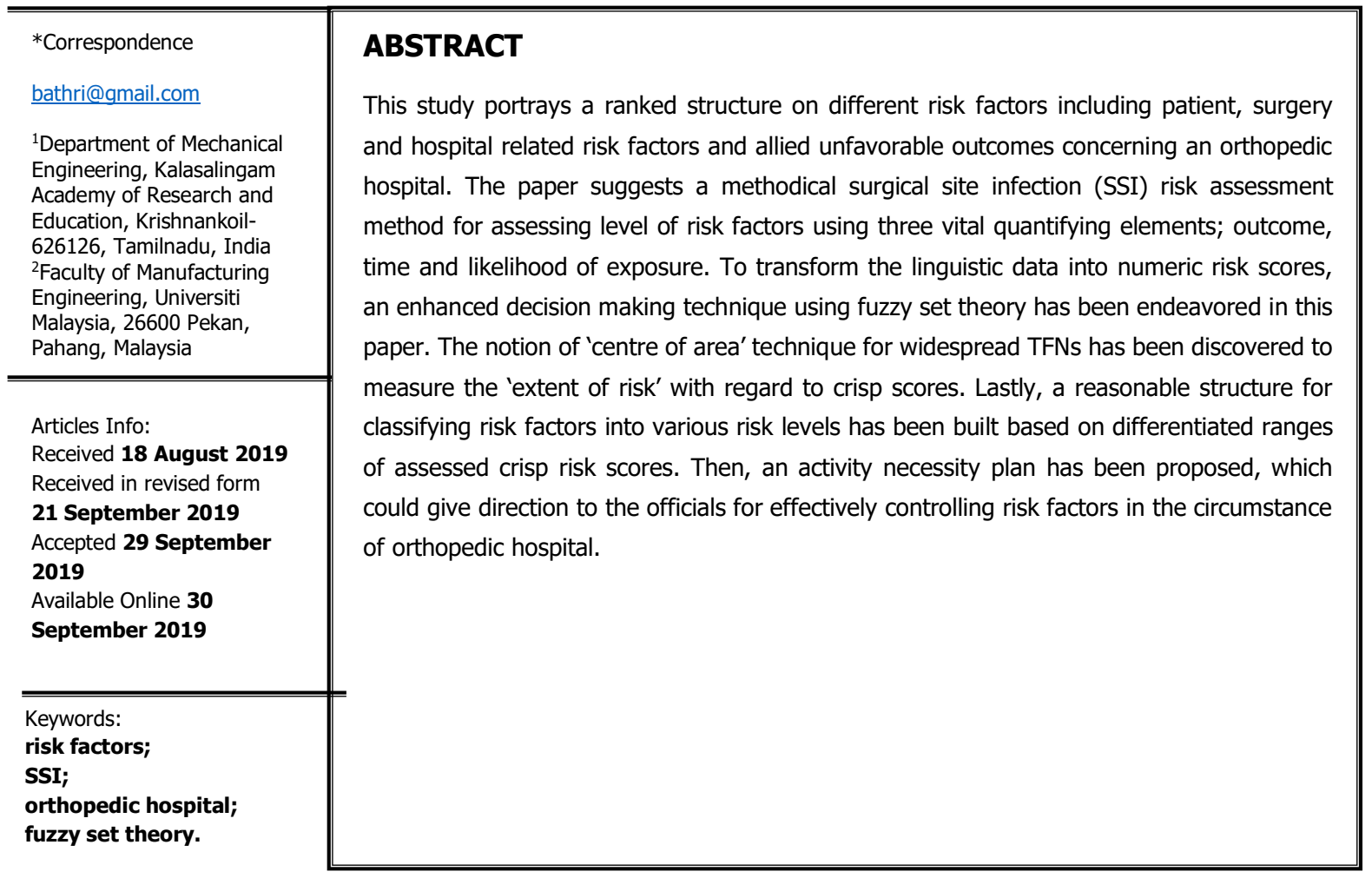

\section{INTRODUCTION}

SSI (Surgical site infection) is considered as the common hospital attained contagion that happens in the premature postoperative time for surgical patients. In other words, it is a contagion happens within a month after the surgery. Contagion in orthopedic surgery is a tragedy for patients as well as physician. This could 
produce enlarged antibiotic usage, protracted hospitalization stay, lengthen therapy, sickness and death (Korol et al., 2013). Though its occurrence has been diminished because of advanced operation theatre amenities and hygienic actions however in emerging countries its frequency is static high. It is well to avert contagion instead of to treat it. Surgical site infection (SSI) upsurge the misery of patients causes an extended stay in sickbay and raise healthcare expenses (De Boer et al., 1999). Additional the risk factors for surgical site infection have been examined by various researchers (Ribeiro et al., 2013; Ercole et al., 2011; Triantafyllopoulos et al., 2015).

Especially orthopedic hospitals, some major risk factors like obesity, prolonged wound contamination, metabolic disorders, long operation time and homologous transfusion influence patient's and employees wellbeing. So, the probabilities that such unfavorable influence is probably to cause, inflicted by different risk factors, can be assessed by the process of effectual surgical site infection risk evaluation module. In a general

perspective, risk evaluation is the method to recognize risk factors present in the work place and also assessing the risks represented by those risk factors and to level them in keeping with the order of significance for the intentions of managing appropriately (British Standards Institutions, 2007). So this paper goals to analyze different patient, surgery and hospital risk factors related to orthopedic hospital. The paper additionally gives a sole fuzzy entrenched risk evaluation procedure with the aim to evaluate the degree of risks using three elements such as outcome, time and likelihood of exposure.

\section{LITERATURE REVIEW}

De Boer et al., (2001) evaluated the comparative risk factors importance for surgical site infection ensuing surgery in the Netherlands. The consequences of the analysis demonstrated that prolonged preoperative stay, infected injury and critical methodical circumstances are the vital risk factors for SSI. Babkin et al., (2007) studied the occurrence and risk factors for SSI following surgery throughout a period of month. From the study, the results exhibited that high injure contagion rate factor seems to be high SSI. Fang et al., (2005) examined to recognize the importance of before and after operative risk factors. Here case study is conducted between 40 patients. The result shows that age above 50 years, smoldering, diabetes, earlier surgical contagion, augmented BMI and alcohol misuse were numerically important risk factors. Jamsen et al., (2009) concluded the risk factors for SSI after surgery. Many re-operations were functioned due to contagion. Masculine patients, patients with a preceding injury and patients with obliged had enlarged rates of contagion following surgery. Minnema et al., (2000) recognize the risk factors related with the improvement of SSI after surgery. The result suggests that preventing the use of operating drainage system and cautious watching of prophylaxis in patients ought to diminish the risk of contagion. Olsen et al., (2008) performed the case study to conclude autonomous risk factors for SSI after surgery. The outcome exposed that diabetes and glucose level for both before and after operative was also autonomously related with an enlarged risk of SSI. Khan et al., (2008) evaluated the risk factors and consequence for SSI after surgery. From the above study, contagion rate was very high and control actions to manage it and increased age, surgery length and smoking are the critical 
risk factors. Kalmeijer et al., (2000) ascertain the comparative consequence of various risk factors for the enhancement of SSI. The findings indicated that elevated nasal carriage, masculine patients and physician are the furthermost vital autonomous risk factor for enhancing SSI. They recognized 15 risk factors in relation to surgical site infection underneath three main headings: patient, surgery and hospital related risk factors.

Thorough literature survey exposes that restricted papers have been stated up to now on comprehending of risk factors and also SSI risk evaluation mainly for orthopedic hospital. The aim of this study is to make an inclusive risk factor comprehending replica related to orthopedic hospital, and also suggest an effectual surgical site infection risk evaluation outline to evaluate the degree of risks throughout the investigation of fuzzy knowledge estimate theory helpful to a subjective risk analysis. Table 1 shows the risk factors for SSI in orthopedic hospital.

Table1 Risk factors for SSI in orthopedic hospital

\begin{tabular}{|c|c|}
\hline Risk Factors & Sub-Factors \\
\hline \multirow{4}{*}{ Patient related factors (PF) } & Increased Age and Gender (PF1) \\
\cline { 2 - 2 } & Obesity (PF2) \\
\cline { 2 - 2 } & Comorbidity (PF3) \\
\cline { 2 - 2 } & Prolonged wound contamination (PF4) \\
\cline { 2 - 2 } & Metabolic disorders (PF5) \\
\hline \multirow{4}{*}{ Surgery related factors (SF) } & Socio economic status (PF6) \\
\cline { 2 - 2 } & Long operation time (SF1) \\
\cline { 2 - 2 } & Antibiotic prophylaxis (SF2) \\
\cline { 2 - 2 } & Type of Anesthesia (SF3) \\
\cline { 2 - 2 } & Postoperative hemotoma formation (SF4) \\
\cline { 2 - 2 } & Homologous transfusion (SF5) \\
\hline Hospital related factors (HF) & Post-operative surveillance (SF6) \\
\hline & Prolonged hospital stay (HF1) \\
\cline { 2 - 2 } & Admission form healthcare facility (HF2) \\
\cline { 2 - 2 } & Hospital \& Surgeon volume of procedures (HF3) \\
\hline
\end{tabular}

\section{Risk factor for surgical site infection risk assessment}

Risk evaluation needs a wide-ranging comprehending of the possible unfavorable health impacts related with unnecessary exposure to a particular risk factor. In broad, the components to deliberate to access a risk evaluation matrix are the probability of the incidence of a risky occasion (exposure) and the seriousness of disorder that can be caused by such occasion (i.e. outcome of exposure). Though, in order to compute a further systematic risk factor risk score, a general equation should be extended. In this study, level of risk degree has been presumed based on the subsequent three fundamental components: outcome of exposure (0), time of exposure (T) and likelihood of exposure (L). Therefore, mathematically, risk can be described as

$$
\begin{aligned}
& \text { Risk }(\mathrm{R})=\text { Outcome }(0) \times \text { Likelihood }(\mathrm{L}) \times \text { Time }(\mathrm{T}) \\
& \text { Risk }(R)=O \times L \times T
\end{aligned}
$$


All of the three exposures might be stated in the interval $[0,1]$, where higher esteem depicts the maximum effect. It can be noticed from equation (1) that the level of risk is near to 0 if an exposure has either small outcome or probability. In this study, the Centre of Area (COA) method (Sanchez et al., 2007; Chu and Varma, 2012) has been used to find the crisp esteem of fuzzy no's because of its ease of execution.

\section{Fuzzy set method}

Zadeh (1965) said that the theory of fuzzy set is mainly involved with the measure of inaccurate and ambiguous data in each problems of decision making. Inaccuracy and ambiguity are intrinsic to the decision makers (DMs) intellectual replica of the subjective evaluation problem underneath study. Thus fuzzy sets include a depiction of impress and/or bias into the replica creation and also solution process (Klir and Folger,

1988; Atanassov, 1986). A fuzzy set $\mathrm{P}$ is described as $P=\left\{\left(\mathrm{y}, \mu_{\mathrm{P}}(y)\right) \mid \mathrm{y} \in V\right\}$, where $\mathrm{V}$ is the universe of discourse, $\mathrm{y}$ is an component in $\mathrm{V}, \mathrm{P}$ is a fuzzy set in $\mathrm{V}, \mu_{p}(y)$ is the membership function of $\mathrm{P}$ at $\mathrm{y}$, in the interim of $[0,1]$. The bigger $\mu_{p}(y)$, the robust the score of membership for component $y$ in a fuzzy set P. Furthermore, a fuzzy no can be described as a fuzzy subset in the universe of discourse $V$ that is both convex and typical. In decision making method, different kinds of fuzzy no's such as Gaussian, trapezoidal and triangular numbers are used for translating the semantic data to qualitative data (Xia et al., 2006). Though, TFN are widely used because of its ease in mathematical depiction and also simple calculation. A TFN P can be signified by $(p, q, r)$ , if membership function $\mu_{p}(y)$ is specified by (chen and chen, 2009):

$$
\mu_{p}(y)=\left\{\begin{array}{c}
(y-p)(q-p), p \leq y \leq q \\
(r-y)(r-q), q \leq y \leq r \\
o, \text { otherwise }
\end{array}\right.
$$

\section{METHODOLOGY}

Phase 1: Recognition of risk factor for SSI equivalent to specific risk affecting agents to create a ranked risk factor risk evaluation module.

Phase 2: Selection of fuzzy semantic scales for all three exposures such as exposure of outcome (0), likelihood (L) and time (T) and also choice of suitable membership function for every exposure.

Phase 3: Gathering of semantic data related to three exposures of every recognized risk factor from the skill of the hospital specialists. Then, these semantic data have been transformed into equivalent fuzzy no's.

Phase 4: Combination of expert's views (semantic data) by using fuzzy combination operators into fuzzy set no's portrayal.

Phase 5: In this phase, all combined fuzzy no's related to all three assessing exposures of every specific risk have been converted into single crisp no's using a technique named 'Centre of Area (COA)', which is pertinent 
for TFN in the theory of fuzzy set. A risk score of every risk factor has been computed by multiplying the crisp values of each assessing exposures and the outcomes acquired thereof has been known as 'crisp risk rating'.

Phase 6: Classification of risk extent scores dependent on the risk factors specific crisp risk scores.

Phase 7: An activity necessity strategy could then be proposed lastly for managing the risk factors regarding various risk extent scores.

\section{Case study}

To verify the suggested surgical site infection risk evaluation approach, a case study has been described concerning an orthopedic hospital (healthcare industry) situated in southern part of India. Also, this orthopedic hospital is the leading one in the nation with average annual surgery of 1000 , with staff strength of 500. With the intention of assist hospital managers in re-assessing condition of different well-being and safety rehearses and founding improved health risk alleviation guidelines, a focus team review has been empirically lead by investigating individual perception of hospital authorities of the said healthcare sector who were effectively allied in orthopedic hospital operations.

In the existing study, a panel of five decision makers has been framed by the healthcare authority to play a part in evaluating and measuring (in fuzzy scale) risk factors for surgical site infection related to the orthopedic hospital. The panel contains five hospital specialists with over 10 years' experience in foresaid operations who contributed in this review. A team of participants have been recognized by the healthcare administrative body two orthopedicians (more than 10 years' experience), two special orthopedic surgeons (more than 15 years' experience) and chief doctor (more than 20 years' experience). Though, all decision makers have been provided the same priority while evaluating decision making data. The participants have been recognized through internal polling of the hospital officials to contribute in such a decision making. The specialist's individualities have not been express here due to its obscurity reasons; therefore, they have been indicated as $\mathrm{DM}_{1}, \mathrm{DM}_{2}, \ldots, \mathrm{DM}_{5}$. The specialists have been asked for to rate their individual point of view in a comprehensive questionnaire (distributed to them) against every one of the specific risk factor regarding their exposure level alluding to a semantic scale. Semantic scale for three exposures is exhibited in Table 2. 
Table2 A seven-point fuzzy semantic scale with equivalent fuzzy no's for all three exposure events Source: Samantra et al., (2017)

\begin{tabular}{|c|c|c|c|}
\hline $\begin{array}{c}\text { Outcome of exposure } \\
\text { [0] }\end{array}$ & Time of exposure [T] & $\begin{array}{c}\text { Likelihood of exposure } \\
{[\mathbf{L}]}\end{array}$ & Triangular fuzzy no's \\
\hline Negligible (N) & Exceptionally Rare (ER) & Not Applicable (NA) & $(0,0,0.1)$ \\
\hline Minor (m) & Rare (R) & Absolutely Low (AL) & $(0,0.1,0.3)$ \\
\hline Marginal (M) & Occasional (OC) & Very Low (VL) & $(0.1,0.3,0.5)$ \\
\hline Serious (S) & Seldom (S) & Low (L) & $(0.3,0.5,0.7)$ \\
\hline Very Serious (VS) & Often (O) & Medium (M) & $(0.5,0.7,0.9)$ \\
\hline Critical (C) & Frequent (F) & High (H) & $(0.7,0.9,1)$ \\
\hline Catastrophic (K) & Prolonged (P) & Very High (VH) & $(0.9,1,1)$ \\
\hline
\end{tabular}

$\begin{array}{lllllll}\text { N } & \mathrm{m} & \mathrm{M} & \mathrm{S} & \mathrm{VS} & \mathrm{C} & \mathrm{K} \\ \mathrm{ER} & \mathrm{R} & \mathrm{OC} & \mathrm{S} & \mathrm{O} & \mathrm{F} & \mathrm{P} \\ \mathrm{NA} & \mathrm{AL} & \mathrm{VL} & \mathrm{L} & \mathrm{M} & \mathrm{H} & \mathrm{VH}\end{array}$

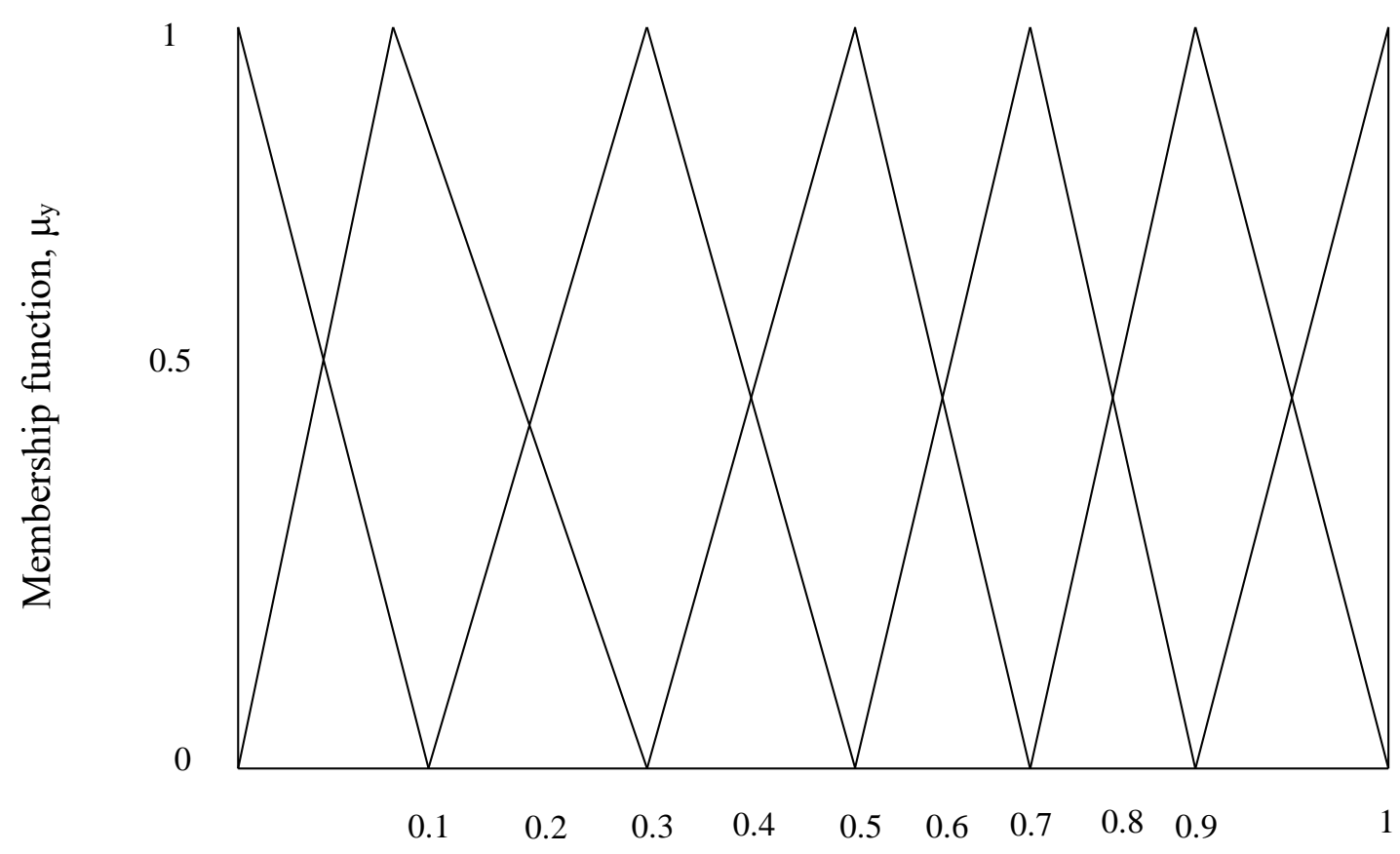

Possible values, (y)

Figure 1 Triangular membership function for three assessing elements $(0, T$ and $L)$ 
Table 3 Outcome of exposure of different risk factors allocated by decision makers in semantic terms

\begin{tabular}{|c|c|c|c|c|c|c|}
\hline Risk Factors & Sub-Factors & DM1 & DM2 & DM3 & DM4 & DM5 \\
\hline \multirow{4}{*}{ Patient } & PF1 & S & M & M & S & M \\
\cline { 2 - 7 } & PF2 & S & VS & S & S & VS \\
\cline { 2 - 7 } & PF3 & VS & S & VS & S & VS \\
\cline { 2 - 7 } & PF4 & C & VS & VS & C & VS \\
\cline { 2 - 7 } & PF5 & VS & S & VS & S & S \\
\cline { 2 - 7 } & PF6 & M & S & S & M & S \\
\hline \multirow{4}{*}{ Surgery } & SF1 & VS & S & S & VS & VS \\
\cline { 2 - 7 } & SF2 & S & S & VS & S & VS \\
\cline { 2 - 7 } & SF3 & C & C & VS & C & VS \\
\cline { 2 - 7 } & SF5 & C & C & C & VS & VS \\
\cline { 2 - 7 } & SF6 & S & VS & S & VS & S \\
\hline \multirow{4}{*}{ Hospital } & HF1 & S & M & M & S & S \\
\cline { 2 - 7 } & HF2 & S & S & M & M & M \\
\cline { 2 - 7 } & HF3 & VS & VS & S & S & S \\
\hline
\end{tabular}

Table 4 Time of exposure of different risk factors allocated by decision makers in semantic terms

\begin{tabular}{|c|c|c|c|c|c|c|}
\hline Risk Factors & Sub-Factors & DM1 & DM2 & DM3 & DM4 & DM5 \\
\hline \multirow[t]{6}{*}{ Patient } & PF1 & 0 & $\mathrm{~S}$ & 0 & $\mathrm{~S}$ & 0 \\
\hline & PF2 & $\mathrm{S}$ & $S$ & 0 & $\mathrm{~S}$ & 0 \\
\hline & PF3 & $\mathrm{S}$ & 0 & $\mathrm{~S}$ & 0 & $\mathrm{~S}$ \\
\hline & PF4 & $\mathrm{P}$ & $\mathrm{F}$ & $\mathrm{F}$ & $\mathrm{P}$ & $\mathrm{P}$ \\
\hline & PF5 & $\mathrm{S}$ & $\mathrm{S}$ & $\mathrm{OC}$ & $\mathrm{S}$ & $\mathrm{S}$ \\
\hline & PF6 & $\mathrm{OC}$ & $\mathrm{OC}$ & $\mathrm{S}$ & $\mathrm{S}$ & $\mathrm{R}$ \\
\hline \multirow[t]{6}{*}{ Surgery } & SF1 & $\mathrm{S}$ & $\mathrm{S}$ & 0 & 0 & $\mathrm{~F}$ \\
\hline & SF2 & 0 & $\mathrm{~F}$ & $\mathrm{~F}$ & $\mathrm{~F}$ & 0 \\
\hline & SF3 & $\mathrm{F}$ & 0 & $\mathrm{~F}$ & 0 & 0 \\
\hline & SF4 & $\mathrm{F}$ & $\mathrm{F}$ & $\mathrm{S}$ & $\mathrm{S}$ & $\mathrm{F}$ \\
\hline & SF5 & $\mathrm{S}$ & 0 & 0 & 0 & $\mathrm{~S}$ \\
\hline & SF6 & 0 & $\mathrm{~F}$ & $\mathrm{~F}$ & 0 & 0 \\
\hline \multirow[t]{3}{*}{ Hospital } & HF1 & $S$ & 0 & $\mathrm{~S}$ & 0 & $S$ \\
\hline & $\mathrm{HF} 2$ & $S$ & $\mathrm{~S}$ & $\mathrm{OC}$ & $\mathrm{OC}$ & $\mathrm{S}$ \\
\hline & HF3 & 0 & 0 & $\mathrm{~F}$ & 0 & $\mathrm{~S}$ \\
\hline
\end{tabular}

Table 5 Likelihood of exposure of different risk factors allocated by decision makers in semantic terms

\begin{tabular}{|c|c|c|c|c|c|c|}
\hline Risk Factors & Sub-Factors & DM1 & DM2 & DM3 & DM4 & DM5 \\
\hline \multirow{4}{*}{ Patient } & PF1 & M & L & M & L & M \\
\cline { 2 - 7 } & PF2 & H & M & M & M & H \\
\cline { 2 - 7 } & PF3 & M & H & H & M & H \\
\cline { 2 - 7 } & PF4 & VH & VH & H & H & H \\
\cline { 2 - 7 } & PF5 & L & L & M & L & M \\
\cline { 2 - 7 } & PF6 & VL & L & L & L & VL \\
\hline \multirow{4}{*}{ Surgery } & SF1 & H & H & M & M & H \\
\cline { 2 - 7 } & SF2 & H & M & M & H & M \\
\cline { 2 - 7 } & SF3 & M & M & L & L & M \\
\cline { 2 - 7 } & SF4 & H & M & H & M & M \\
\cline { 2 - 7 } & SF5 & L & L & M & M & L \\
\hline
\end{tabular}




\begin{tabular}{|l|l|l|l|l|l|l|}
\hline & SF6 & M & M & L & L & M \\
\hline \multirow{3}{*}{ Hospital } & HF1 & H & H & M & M & M \\
\cline { 2 - 7 } & HF2 & L & L & L & M & M \\
\cline { 2 - 7 } & HF3 & H & H & M & M & H \\
\hline
\end{tabular}

Combination is the process of joined the fuzzy sets to frame a sole combined inclination fuzzy set. Supposing that $\mathrm{g}$ is the no of decision makers $\left(\mathrm{DM}_{\mathrm{s}}, \mathrm{s}=1, \ldots, \mathrm{g}\right)$, who are allocated to evaluate $\mathrm{m}$ job-related risk factors $\left(\mathrm{R}(\mathrm{S})_{\mathrm{e}}, \mathrm{e}=1, \ldots, \mathrm{m}\right)$, with subsequent $\mathrm{f}^{\text {th }}$ exposure $(\mathrm{f} \approx 0, \mathrm{~T}$ and $\mathrm{L})$ to particular risk factors $\left(\mathrm{S}(\mathrm{y})_{\mathrm{e}}, \mathrm{e}=1\right.$, ..., m) underneath a certain collection of risk factors affecting agent (y), the fundamental formulation for computing the combined fuzzy inclinations $\left(S(y)_{e}\right)_{f}$ of th exposure to risks can be utilized as pursues (Hsu and Chen, 1996):

$$
\left(S(y)_{e}\right)_{f}=\frac{1}{g}\left[S(y)_{e f 1} \oplus S(y)_{e f 2} \oplus \ldots \oplus S(y)_{e f g}\right]
$$

For instance, combined inclination of Outcome of exposure (C);

$$
\left(S(y)_{e}\right)_{f \approx I}=\frac{1}{g}\left[S(y)_{e f 1} \oplus S(y)_{e f 2} \oplus \ldots \oplus S(y)_{e f g}\right]
$$

Additionally, the extent of risk or risk score of every specific risk factors can be computed by their exposure events using the subsequent relation:

$$
\text { Risk score, } R(S)_{e}=\left(O_{\text {crisp }} \otimes T_{\text {crisp }} \otimes L_{\text {crisp }}\right)_{e}
$$

The outcomes of combined fuzzy inclinations, crisp esteems and risk scores have been appeared in Table6. So, a graphical portrayal of exposure event related to patient related risk factors has been mapped to comprehend the extent of exposure outcome against the time of exposure and also the likelihood of exposure as appeared in fig2. 
Table 6 Combined inclinations of five decision makers for exposure measures in fuzzy no's equivalent risk factors risk scores regarding crisp esteems

\begin{tabular}{|c|c|c|c|c|c|c|c|c|c|}
\hline \multirow{2}{*}{$\begin{array}{c}\text { Risk } \\
\text { Factors }\end{array}$} & \multirow[t]{2}{*}{ Sub-Factors } & \multicolumn{3}{|c|}{ Fuzzy No's } & \multicolumn{3}{|c|}{ Crisp esteems } & \multirow{2}{*}{$\begin{array}{r}\text { Risk Score } \\
R=C \times E \times P\end{array}$} & \multirow{2}{*}{$\begin{array}{l}\text { Percentage of } \\
\text { Contribution }\end{array}$} \\
\hline & & $\begin{array}{c}\text { Outcome of } \\
\text { Exposure [O] }\end{array}$ & $\begin{array}{c}\text { Time of } \\
\text { Exposure [T] }\end{array}$ & $\begin{array}{l}\text { Likelihood of } \\
\text { Exposure [L] } \\
\end{array}$ & $\mathbf{O}$ & $\mathbf{T}$ & $\mathbf{L}$ & & \\
\hline \multirow[t]{6}{*}{ Patient } & PF1 & $(0.18,0.38,0.58)$ & $(0.42,0.62,0.82)$ & $(0.42,0.62,0.82)$ & 0.38 & 0.62 & 0.62 & 0.1460 & \multirow{6}{*}{$40.3 \%$} \\
\hline & PF2 & $(0.38,0.58,0.78)$ & $(0.78,0.78,0.78)$ & $(0.58,0.78,0.94)$ & 0.58 & 0.78 & 0.76 & 0.3468 & \\
\hline & PF3 & $(0.42,0.62,0.82)$ & $(0.78,0.78,0.78)$ & $(0.62,0.82,0.96)$ & 0.62 & 0.78 & 0.8 & 0.3868 & \\
\hline & PF4 & $(0.58,0.78,0.94)$ & $(0.82,0.96,1)$ & $(0.78,0.94,1)$ & 0.76 & 0.92 & 0.90 & 0.6441 & \\
\hline & PF5 & $(0.38,0.62,0.82)$ & $(0.26,0.46,0.66)$ & $(0.38,0.58,0.78)$ & 0.60 & 0.46 & 0.58 & 0.1618 & \\
\hline & PF6 & $(0.22,0.42,0.62)$ & $(0.16,0.34,0.54)$ & $(0.22,0.42,0.62)$ & 0.42 & 0.34 & 0.42 & 0.0611 & \\
\hline \multirow[t]{6}{*}{ Surgery } & SF1 & $(0,42,0.62,0.82)$ & $(0.46,0.66,0.84)$ & $(0.62,0.82,0.96)$ & 0.62 & 0.65 & 0.8 & 0.3240 & \multirow{6}{*}{$45.82 \%$} \\
\hline & SF2 & $(0.38,0.58,0.78)$ & $(0.62,0.82,0.96)$ & $(0.58,0.78,0.94)$ & 0.58 & 0.8 & 0.76 & 0.3557 & \\
\hline & SF3 & $(0.62,0.82,0.96)$ & $(0.58,0.78,0.94)$ & $(0.42,0.62,0.82)$ & 0.8 & 0.76 & 0.62 & 0.3802 & \\
\hline & SF4 & $(0.62,0.82,0.96)$ & $(0.54,0.74,0.88)$ & $(0.58,0.78,0.94)$ & 0.8 & 0.72 & 0.76 & 0.4416 & \\
\hline & SF5 & $(0.38,0.58,0.78)$ & $(0.42,0.62,0.82)$ & $(0.38,0.58,0.78)$ & 0.58 & 0.62 & 0.58 & 0.2085 & \\
\hline & SF6 & $(0.38,0.58,0.78)$ & $(0.58,0.78,0.94)$ & $(0,42,0.62,0.82)$ & 0.58 & 0.76 & 0.62 & 0.2756 & \\
\hline \multirow[t]{3}{*}{ Hospital } & HF1 & $(0.22,0.42,0.62)$ & $(0.38,0.58,0.78)$ & $(0.58,0.78,0.94)$ & 0.42 & 0.58 & 0.76 & 0.1867 & \multirow{3}{*}{$13.86 \%$} \\
\hline & HF2 & $(0.18,0.38,0.58)$ & $(0.22,0.42,0.62)$ & $(0.38,0.58,0.78)$ & 0.38 & 0.42 & 0.58 & 0.092 & \\
\hline & HF3 & $(0.38,0.58,0.78)$ & $(0.5,0.7,0.88)$ & $(0.62,0.82,0.96)$ & 0.58 & 0.69 & 0.8 & 0.321 & \\
\hline \multicolumn{8}{|c|}{ Overall risks } & 4.3338 & \\
\hline
\end{tabular}


Furthermore, risk score of the recognized risk factors related to various risk agents (patient, surgery, hospital) can be simply comprehended by Fig 5-7 correspondingly. It has been noticed by fig3, the patient risk factors like prolonged wound contamination (PF4), Comorbidity (PF3), Obesity (PF2) and Metabolic disorders (PF5) are probably to enforce unfavorable impacts to the patients' health because of their high esteem of risk score. Additionally, factors like increased age and gender (PF1) and socio economic status ( $\mathrm{PF} 6$ ) have sensible or less pessimistic influence to the patient health yet critical to specific working environment circumstances.

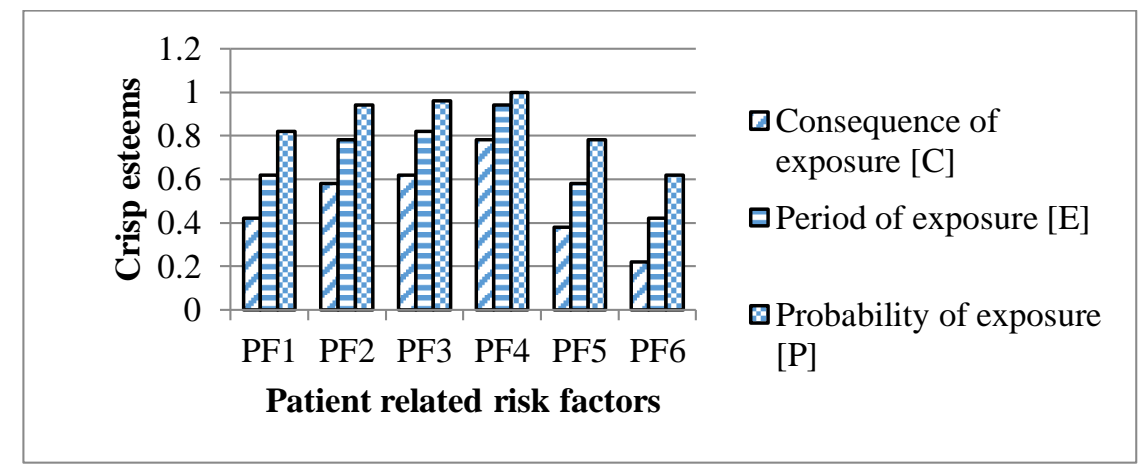

Figure 2 Difference of extent of exposure related to patient related factors

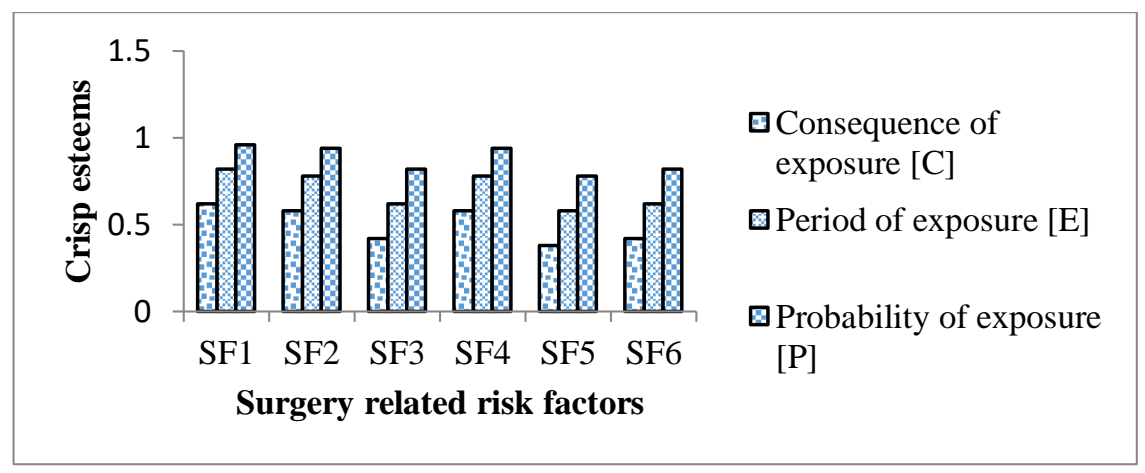

Figure 3 Difference of extent of exposure related to surgery related factors

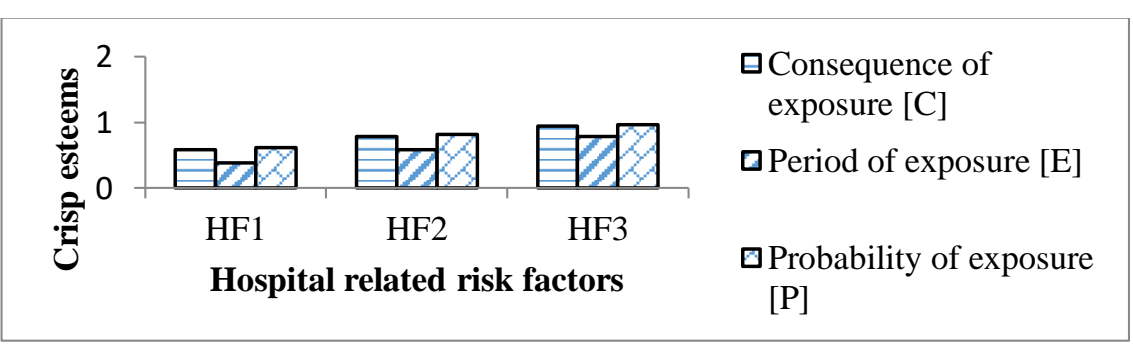

Figure 4 Difference of extent of exposure related to hospital related factors

Likewise, it is obviously comprehended by fig 6-7 that risks like postoperative hemotoma formation (SF4), type of anesthesia (SF3) and antibiotic prophylaxis (SF2) from surgery related risk factors; hospital and surgeon volume of procedures (HF3) and prolonged hospital stay (HF1) from hospital related risk factors enforce acute pessimistic influence to the hospital management as well as patients. The esteem (risk degree) that is calculated subsequent to every risk agent specifies weighted average. The acquired outcomes are provided in Table6. It can be noticed that surgery related risk factors have the maximum risk 
score (1.9859), which can enforce maximum unfavorable impacts on employee's health as well as patients amid the three risk agents. Its percentage involvement is about $45.82 \%$ to the total risk factors. The agent teams like patient related risk factors are placing $2^{\text {nd }}$ most percentage and hospital related risk factor has least influence to the total risk esteem. The percentage of involvement of every recognized risk factor on total risks can be comprehended by fig8. So, the risk agent with the maximum value of risk score is the main source that should be removed/reduced first than the other risk factors. Likewise, in the risk agent (team), risk factors with maximum risk score should be managed initially by reducing their exposure to risk factors.

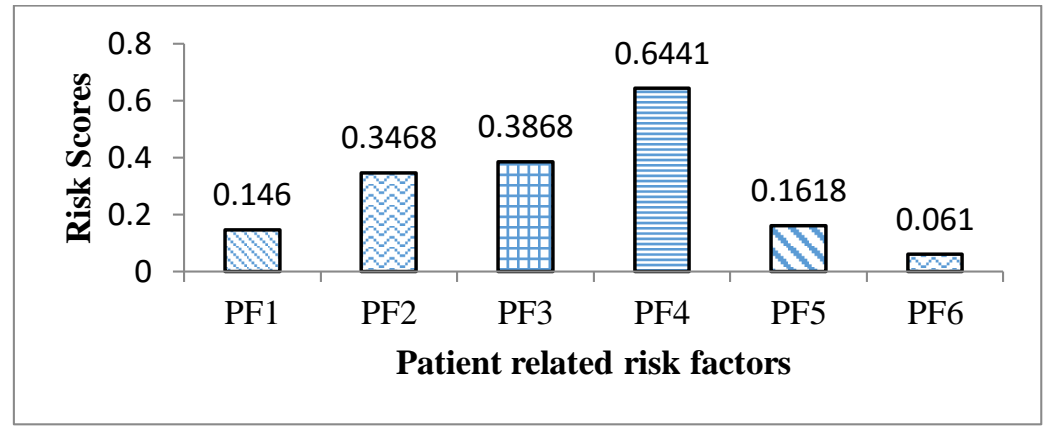

Figure 5 Risk score of different patient related factors

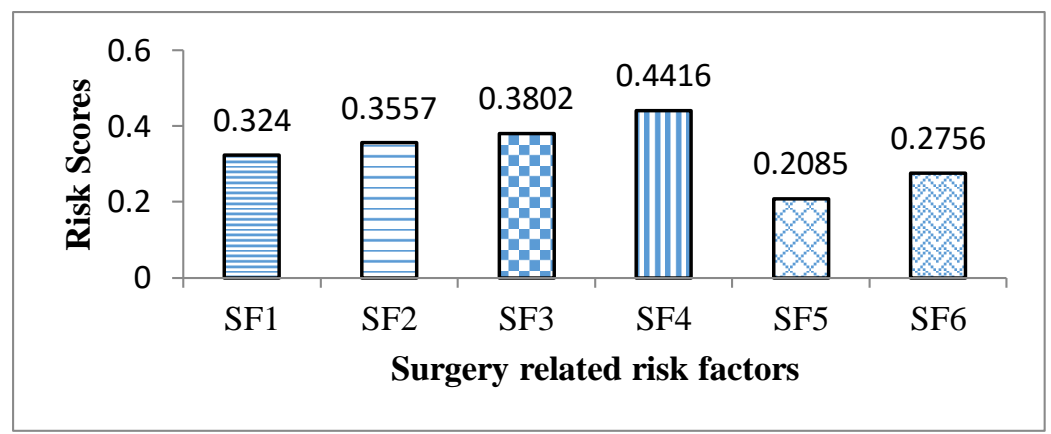

Figure 6 Risk score of different surgery related factors

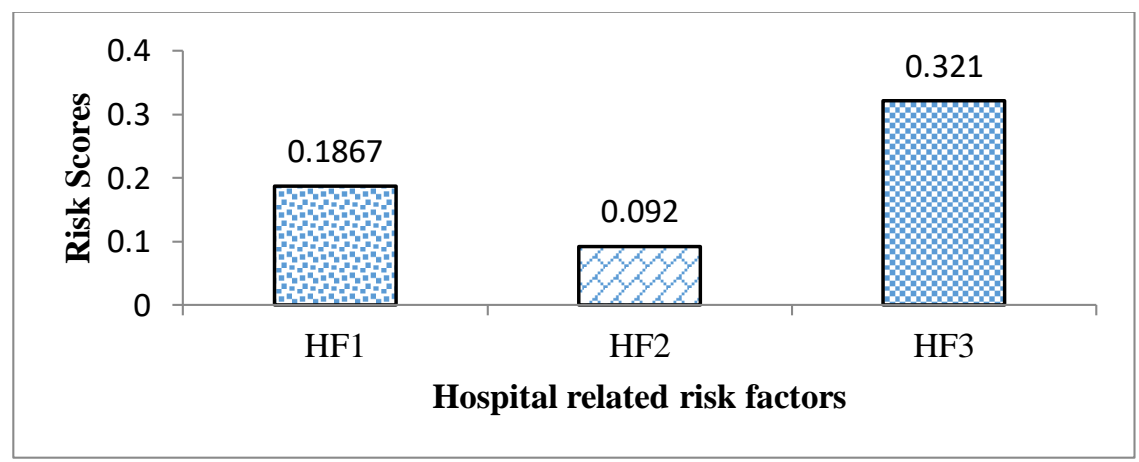

Figure 7 Risk score of different hospital related factors 


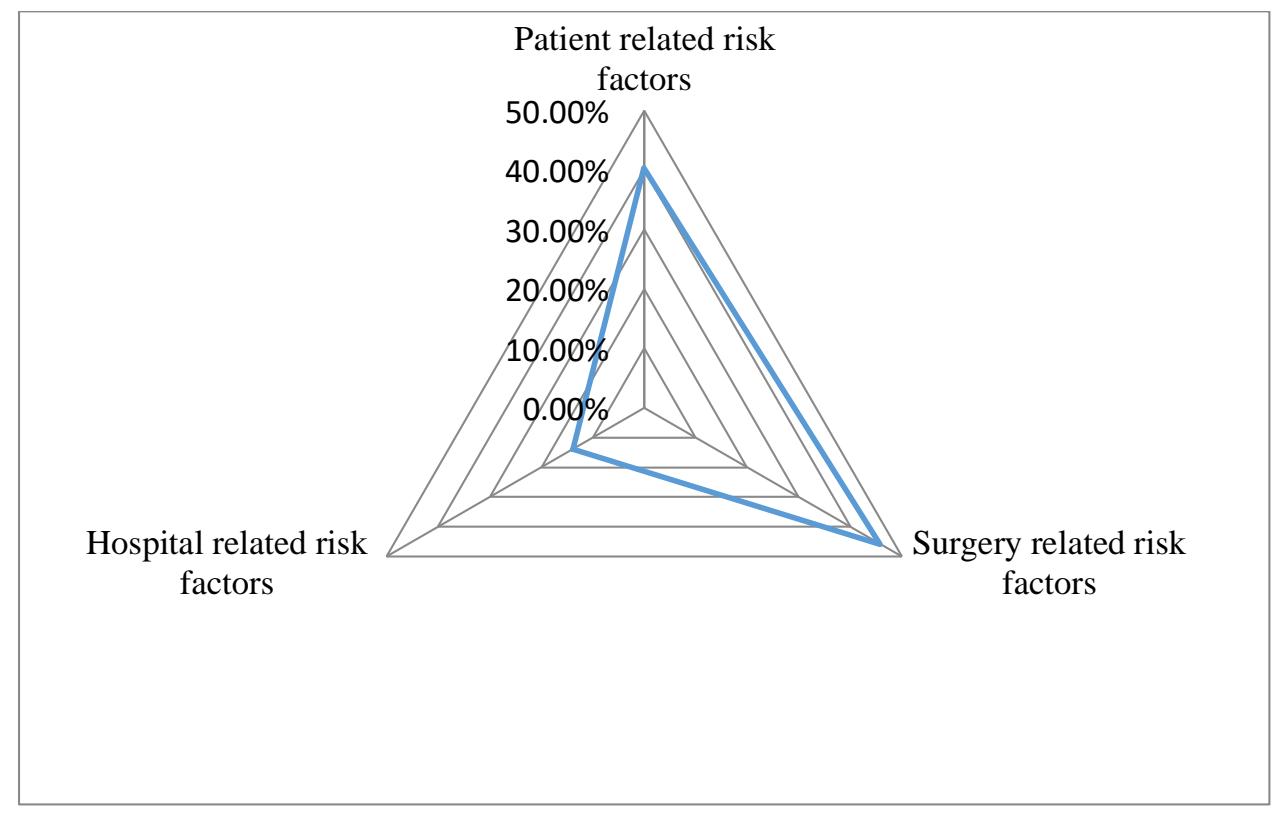

Figure 8 Percentage of contribution of different risk factors to the complete risk factors

Table 7 Risk score (crisp) esteems for semantic risk evaluation scale

\begin{tabular}{|c|c|c|c|c|}
\hline $\begin{array}{c}\text { Triangular fuzzy } \\
\text { no's }\end{array}$ & $\begin{array}{c}\text { Outcome of } \\
\text { exposure [0] }\end{array}$ & $\begin{array}{c}\text { Time of exposure } \\
{[\mathbf{T}]}\end{array}$ & $\begin{array}{c}\text { Likelihood of } \\
\text { exposure [L] }\end{array}$ & $\begin{array}{c}\text { Risk score } \\
\text { (R= 0 x T x L) }\end{array}$ \\
\hline$(0.9,1,1)$ & 0.9666 & 0.9666 & 0.9666 & 0.9032 \\
\hline$(0.7,0.9,1)$ & 0.8666 & 0.8666 & 0.8666 & 0.6509 \\
\hline$(0.5,0.7,0.9)$ & 0.7 & 0.7 & 0.7 & 0.343 \\
\hline$(0.3,0.5,0.7)$ & 0.3 & 0.3 & 0.3 & 0.125 \\
\hline$(0.1,0.3,0.5)$ & 0.5 & 0.5 & 0.5 & 0.027 \\
\hline$(0,0.1,0.3)$ & 0.1333 & 0.1333 & 0.1333 & 0.00237 \\
\hline$(0,0,0.1)$ & 0.0333 & 0.0333 & 0.0333 & 0.000037 \\
\hline
\end{tabular}

Prior to the choosing of any control choices, all risk factors that evaluated ought to be classified in various risk level classification dependent on the different ranges of risk rating. Usually, risk score ranges would be chosen from the semantic parametric scale (Table2). Therefore, risk score values (crisp) for semantic risk evaluation have been obtainable in Table 7. Here, crisp esteems have also been computed using Centre of Area technique and it has been noticed that 0.9032 seems to be utmost risk score that can be allocated to particular risk factors. Then five various risk extent categories have been chosen on the basis of five various risk score ranges from the total range of (0-0.9032) as appeared in Table 8.

So, recognition of different risk factors underneath every level classifications and proposed control activities has been obtainable in Table 9. 
Table 8 Risk extent score

\begin{tabular}{|c|c|}
\hline Risk level & Risk rating ranges (crisp) \\
\hline Very Low & $(0-0.027)$ \\
\hline Low & $(0.125-0.027)$ \\
\hline Moderate & $(0.343-0.125)$ \\
\hline High & $(0.6509-0.343)$ \\
\hline Critical & $(0.9032-0.6509)$ \\
\hline
\end{tabular}

The efficiency of recommended activity necessity strategy can be verified throughout systematic surveys and also discussion with staffs.

Figure 9 depicts an overall ranking of controls suggested by Safe Work Australia (Australia 2011), in which methods of monitoring risks from top extent of safeguard and dependability to the bottom is hierarchical.

Table 9 Risk factors are appropriate in different risk extent scores and proposed activity necessity strategy for managing the risks

\begin{tabular}{|c|c|l|}
\hline $\begin{array}{c}\text { Risk extent } \\
\text { scores }\end{array}$ & Risk factors & \multicolumn{1}{|c|}{ Needed action } \\
\hline Critical & Not identified & $\begin{array}{l}\text { Prompt action obligatory. Entrance to the risk ought to be } \\
\text { limited till the risk can be reduced to an adequate range. Petite } \\
\text { duration action might be needed to bring down the risk degree } \\
\text { and then intermediate and extensive duration strategies to } \\
\text { manage the risk to as low as sensibly feasible using the ranking } \\
\text { of controls. }\end{array}$ \\
\hline High & PF2, PF3, PF4, SF2, & $\begin{array}{l}\text { Action required rapidly (inside 3days). The process oughtn't to } \\
\text { ensure if the risk is evaluated and control choices chosen } \\
\text { dependent on the ranking of controls. }\end{array}$ \\
\hline Moderate & PF1, PF3, SF1, SF5, & $\begin{array}{l}\text { Action obligatory inside 7days to remove or lessen the risk. } \\
\text { SF6, HF1, HF3 }\end{array}$ \\
\hline Low & PF6, HF2 & $\begin{array}{l}\text { Action needed within a sensible period framework (1 to 3 } \\
\text { weeks) for removing or lessening the risks. }\end{array}$ \\
\hline Very low & Not identified & $\begin{array}{l}\text { Risks to be removed or reduced when conceivable using the } \\
\text { ranking of controls. }\end{array}$ \\
\hline
\end{tabular}




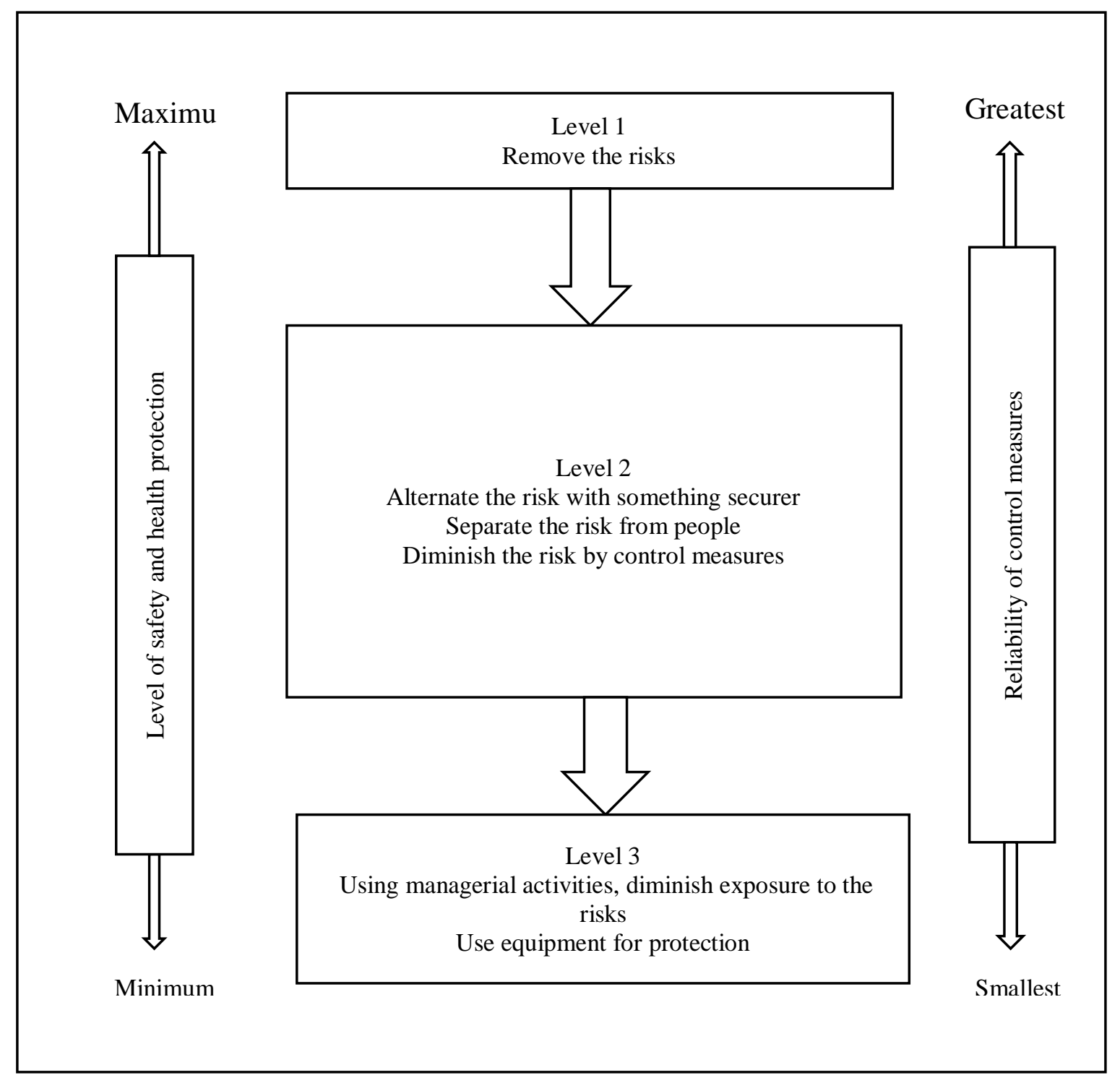

Figure 9 Ranking of controls

The above-mentioned ranking of controls is a general one. It can be used in the circumstances where risk data is obviously described. In this paper, the suggested activity necessity strategy (Table 9) defines the data pertinent to the recognized hazards comprising their environment and also the extent of risks.

\section{CONCLUSIONS}

An effective risk factors for surgical site infection risk assessment approach has been suggested in this to compute the degree of risk from the evaluation of exposure to risk factors related to a case of orthopedic hospital in India. The suggested subjective risk evaluation method based on fuzzy has seemed as more pragmatic than conventional measurable techniques meanwhile it uses specialist decisions in individual manner instead of unbiased. The notion of fuzzy set method aided to carefully manage the doubt and vagueness comprised in individual human decision. The acquired outcome of risk evaluation shows 
that high level risk score should initially be managed with the aim to improve the well-being and protection in the work environment. So, this paper has presented a reasonable and methodical classification of recognized risk factors ensued by effectual control measures for handling risks; appears to be very helpful for hospital officials. The notion of ranking of risk controls are used in this paper to give a basic idea to the managers for successful chosen and execution of suggested risk prevention measures.

In this paper, the suggested approach used for surgical site infection risk assessment is a general one. Though, the categorization of risk factors towards risk evaluation is genuinely industry precise. This paper promotes a wide-ranging risk management method for effectively recognizing risk factors, surveying risks and its preventive actions, which could give rules to the officials for successful administration of risk factors and their related risks for the development of patient's and employee health at the hospitals.

The drawbacks of the paper are discussed below:

This paper exposes a subjective risk evaluation module in fuzzy setting. Different risks like surgery, patient and hospital related risk factors and associated outcomes, conditions of happening have been deliberated. Risk factors have been individually evaluated regarding outcome, time and likelihood of exposure. Though, in therapeutic sciences, there are few pointers like ASI score, body mass index (BMI), diabetes level, blood pressure (BP) and risk ratio often used for health risk examines. Previously mentioned risk factors are genuinely quantifiable dependent on actual data. The objective of this paper is qualitative assessment of risk factors in fuzzy setting. Risk measurements like outcome, time and likelihood of exposure have been evaluated individually instead of unbiased. Hence ASA, diabetes level, BMI, BP, risk ratio etc. have not been deliberated in this paper. A more crucial measurable risk analysis on factors for SSI may include these features in upcoming work.

\section{References}

1. Korol, E., Johnston, K., Waser, N., Sifakis, F., Jafri, H. S., Lo, M., \& Kyaw, M. H. (2013). A systematic review of risk factors associated with surgical site infections among surgical patients. PloS one, 8(12), e83743.

2. de Boer, A. S., Mintjes-de Groot, A. J., Severijnen, A. J., van den Berg, J. M. J., \& van Pelt, W. (1999). Risk assessment for surgical-site infections in orthopedic patients. Infection Control \& Hospital Epidemiology, 20(6), 402-407.

3. Ribeiro, J. C., Santos, C. B. D., Bellusse, G. C., Rezende, V. D. F., \& Galvão, C. M. (2013). Occurrence and risk factors for surgical site infection in orthopedic surgery. Acta Paulista de Enfermagem, 26(4), 353359.

4. Ercole, F. F., Franco, L. M. C., Macieira, T. G. R., Wenceslau, L. C. C., Resende, H. I. N. D., \& Chianca, T. C. M. (2011). Risk of surgical site infection in patients undergoing orthopedic surgery. Revista latinoamericana de enfermagem, 19(6), 1362-1368.

5. Triantafyllopoulos, G., Stundner, O., Memtsoudis, S., \& Poultsides, L. A. (2015). Patient, surgery, and hospital related risk factors for surgical site infections following total hip arthroplasty. The Scientific World Journal, 2015.

6. British Standards Institution. (2008). BS OHSAS 18002: 2008 Occupational Health and Safety Management Systems: Guidelines for the Implementation of OHSAS 18001: 2007. British Standards Institution.

7. De Boer, A. S., Geubbels, E. L. P. E., Wille, J., \& Mintjes-de Groot, A. J. (2001). Risk assessment for surgical site infections following total hip and total knee prostheses. Journal of Chemotherapy, 13(sup4), 42-47.

8. Babkin, Y., Raveh, D., Lifschitz, M., Itzchaki, M., Wiener-Well, Y., Kopuit, P., ... \& Yinnon, A. M. (2007). Incidence and risk factors for surgical infection after total knee replacement. Scandinavian journal of infectious diseases, 39(10), 890-895. 
9. Fang, A., Hu, S. S., Endres, N., \& Bradford, D. S. (2005). Risk factors for infection after spinal surgery. Spine, 30(12), 1460-1465.

10. Jämsen, E., Huhtala, H., Puolakka, T., \& Moilanen, T. (2009). Risk factors for infection after knee arthroplasty: a register-based analysis of 43,149 cases. JBJS, 91(1), 38-47.

11. Minnema, B., Vearncombe, M., Augustin, A., Gollish, J., \& Simor, A. E. (2004). Risk factors for surgicalsite infection following primary total knee arthroplasty. Infection Control \& Hospital Epidemiology, 25(6), 477-480.

12. Olsen, M. A., Nepple, J. J., Riew, K. D., Lenke, L. G., Bridwell, K. H., Mayfield, J., \& Fraser, V. J. (2008). Risk factors for surgical site infection following orthopaedic spinal operations. JBJS, 90(1), 62-69.

13. Khan, M. S., Rehman, S., Ali, M. A., Sultan, B., \& Sultan, S. (2008). Infection in orthopedic implant surgery, its risk factors and outcome. J Ayub Med Coll Abbottabad, 20(1), 23-5.

14. Kalmeijer, M. D., van Nieuwland-Bollen, E., Bogaers-Hofman, D., de Baere, G. A., \& Kluytmans, J. A. (2000). Nasal carriage of Staphylococcus aureus: Is a major risk factor for surgical-site infections in orthopedic surgery. Infection Control \& Hospital Epidemiology, 21(5), 319-323.

15. Sánchez, J. Á., Mira, J. M., de la Paz López, F., \& Troncoso, J. C. (2007). The centre of area method as a basic mechanism for representation and navigation. Robotics and Autonomous Systems, 55(12), 860869.

16. Chu, T. C., \& Varma, R. (2012). Evaluating suppliers via a multiple levels multiple criteria decision making method under fuzzy environment. Computers \& Industrial Engineering, 62(2), 653-660.

17. Zadeh, L. A. (1965). Fuzzy sets. Information and control, 8(3), 338-353.

18. Klir, G. J., \& Folger, T. A. (1988). Fuzzy sets, uncertainty, and information.

19. Atanassov, K. T. (1986). Intuitionistic fuzzy sets. Fuzzy sets and Systems, 20(1), 87-96.

20. Xia, H. C., Li, D. F., Zhou, J. Y., \& Wang, J. M. (2006). Fuzzy LINMAP method for multiattribute decision making under fuzzy environments. Journal of Computer and System Sciences, 72(4), 741-759.

21. Chen, S. M., \& Chen, J. H. (2009). Fuzzy risk analysis based on ranking generalized fuzzy numbers with different heights and different spreads. Expert systems with applications, 36(3), 6833-6842.

22. Samantra, C., Datta, S., \& Mahapatra, S. S. (2017). Analysis of occupational health hazards and associated risks in fuzzy environment: a case research in an Indian underground coal mine. International journal of injury control and safety promotion, 24(3), 311-327.

23. Hsu, H. M., \& Chen, C. T. (1996). Aggregation of fuzzy opinions under group decision making. Fuzzy sets and systems, $79(3), 279-285$.

24. Australia, S. W. How to Manage Work Health and Safety Risks: Code of Practice. Safe Work Australia publications. 2011. 